\title{
Spray performance and steadiness of an effervescent atomizer and an air- core-liquid-ring atomizer for application in spray drying processes of highly concentrated feeds
}

\author{
Marc O. Wittner*, Heike P. Karbstein, Volker Gaukel \\ Karlsruhe Institute of Technology, Institute of Process Engineering in Life Sciences, Chair I: Food Process Engineering, Kaiserstrasse 12, 76131, Karlsruhe, Germany
}

A R T I C L E IN F O

Keywords:

Spray drying

Pneumatic atomization

ACLR atomizer

Effervescent atomizer

High viscous feeds

Highly concentrated feeds

\begin{abstract}
A B S T R A C T
Atomization for spray drying of high viscous feed liquids is still a challenging task. For this reason, we investigated the potential of two internal mixing pneumatic atomizers, namely an effervescent atomizer (EA) and an Air-Core-Liquid-Ring (ACLR) atomizer. Both atomizers are characterized by a two-phase flow in the exit orifice. While this can be either a two-phase plug or annular flow in case of the EA geometry, the ACLR atomizer enforces annular flow conditions. In this study, spraying experiments were conducted at liquid viscosities between 0.12 and $0.69 \mathrm{~Pa}$. The investigations were performed at a constant liquid flow rate of $20 \mathrm{~L} / \mathrm{h}$ and gas pressures from 0.3 to $0.9 \mathrm{MPa}$. Besides the commonly used correlation between Gas-to-Liquid-Ratio (GLR) and time-averaged Sauter mean diameters $(\overline{S M D})$, we analyzed in-depth the time dependent fluctuation of SMDs, as steady atomization is crucial for spray drying applications. We can conclude that due to strong fluctuations of the SMDs the EA is not suitable for the aimed application in spray drying of high viscous feed liquids. In contrast, the ACLR atomizer is a very promising nozzle for spray drying applications as it delivers much better performance and steadiness also at high liquid viscosities.
\end{abstract}

\section{Introduction}

Spray drying is a widely used processing technique for the pro duction of powdered products from liquid sources [1]. The process can be split in three main steps: Namely atomization, drying and powder separation. Atomization of the bulk liquid into small droplets leads to a drastic enlargement of the surface to volume ratio, enhancing heat and mass transport in the subsequent convective drying step. As for all drying processes, water removal is a very energy consuming process, especially as internal energy recovery is restricted in spray drying $[2,3]$. Moreover, the powder throughput of a spray dryer is limited by its specific water evaporation rate at given process conditions. Due to these facts, users from industry demand to increase the feed dry matter content to the highest possible value, prior to the actual spray drying process [4]. For this purpose, more energy efficient processing techni ques like multi stage falling film evaporators or membrane reactors can be used [5]. However, with increasing feed dry matter, the viscosity of most liquids rises strongly, especially in the spray drying dry matter range above $40 \%$. An increase in viscosity complicates atomization, as higher inner friction forces lead to a higher demand of energy for drop formation. Hence, under constant atomization conditions larger droplets and wider droplet size distributions are formed with increasing viscosity. With increasing width of the droplet size distribution, the difference of drying time between the smallest and the largest droplets increases. This complicates uniform drying of the droplets, leading to either overdrying of small droplets at high residence times or in complete drying of large droplets at short residence times. Incompletely dried particles often show an enhanced stickiness, leading to material depositions within the dryer and therefore to material losses and pro cess disturbances. Thus narrow droplet size distributions are required for efficient spray drying, also at high liquid viscosities [1].

For atomization, several types of spraying nozzles are available. A commonly used nozzle for spray drying processes is the hollow cone pressure swirl nozzle [4]. However, this type of nozzle is very limited in the maximum processable viscosity. According to Bayvel and Orze chowski [6] this limiting viscosity is around 0.03 Pas.

For high viscous liquids, the use of external mixing pneumatic atomizers is often recommended. In this type of atomizer, the energy for liquid disintegration is delivered by a fast flowing gas stream, which gets in contact with the liquid outside the nozzle. Yet, high gas con sumption rates, even at low liquid viscosities, lead to an approximately 20 times higher energy consumption, compared to pressure swirl

\footnotetext{
*Corresponding author at: Institute of Engineering in Life Sciences, Section I: Food Process Engineering, Karlsruhe Institute of Technology, Kaiserstrasse 12, 76131, Karlsruhe, Germany.

E-mail address: marc.wittner@kit.edu (M.O. Wittner).
} 
nozzles [1]. This results in high operating costs. Consequently, this type of atomizer is only used under special conditions, like in laboratory or pilot scale spray dryers with very short residence times. Internal mixing pneumatic atomizers (IMP) are reported to offer the possibility to ato mize liquids of higher viscosities at low gas injection rates. In this type of atomizer, feed liquid and compressed gas are injected into a mixing chamber and leave the nozzle through the exit orifice in a two phase flow. However, to the best of our knowledge IMP nozzles are not commonly used in spray drying processes. Several gas injection geo metries have been suggested so far [ $\left[\begin{array}{ll}71\end{array}\right]$.

One promising IMP geometry is the effervescent atomizer (EA), originally invented in the field of combustion science [7]. Several in vestigations on the adaptation of this atomizer for spray drying pro cesses have been published in the last years [12 16$]$. In an EA, a mixing chamber with multiple holes is used to inject the atomization gas stream at low relative velocity into the liquid flow (see Fig. 1).

A two phase flow is formed in the mixing chamber and develops throughout the exit orifice that is placed some way downstream [17]. Resulting spray characteristics are directly linked to the flow pattern inside the exit orifice, which in turn depends on the two phase flow in the mixing chamber (e.g. [18 20]). According to literature, bubbly, plug and annular flow regimes are found, dependent on gas to liquid ratio by mass (GLR) and liquid viscosity $[12,21,22]$. For constant spray droplet size distributions, a steady annular flow in the exit orifice is favored [20]. Under this condition, a thin liquid lamella around a gas core is obtained which is disintegrated into filaments and droplets after leaving the nozzle. However, Stähle et al. [20] showed, that no constant annular flow is generated inside the mixing chamber at low GLRs and viscosities higher than 0.06 Pa-s. Under these conditions, the gas core inside the mixing chamber is interrupted by liquid bridges, resulting in a plug flow.

Based on these findings, a further developed gas injection geometry was proposed, in order to ensure annular flow patterns, even at high viscosities and low GLRs. In this so called Air Core Liquid Ring (ACLR) atomizer, a capillary is used for direct injection of a continuous gas core in the middle of the liquid stream, shortly before the exit orifice [16]. A scheme of the used ACLR atomizer is given in Fig. 2.

Hence, by use of the ACLR geometry the favorable annular flow is present over the complete investigated parameter range with viscosities between 0.001 and $0.308 \mathrm{~Pa}$.s and GLRs from 0.015 to 0.414 [16]. However, regardless of the observed flow conditions, similar values of the time averaged Sauter mean diameter $(\overline{S M D})$ were reached for both types of atomizers in the named study. Nevertheless, the ACLR atomizer delivered steadier mean droplet sizes. Based on these results, the au thors stated, that only the ACLR atomizer might deliver spray droplet sizes, which are steady enough for application in spray drying processes [16].

In this study, we investigated whether this promising atomization concept can be used for spray drying application. Stähle et al. in vestigated the atomization process as a separate process. Therefore, the GLR could be varied by variation of the liquid flow rate at constant gas pressure. In this procedure, influences of different gas expansion po tentials are eliminated. However, in industrial spray drying, the feed flow rate is fixed by the water evaporation capacity of the spray dryer. This water evaporation rate is required by the drying process, in order to ensure steady state operation. We thus varied the GLR by varying the gas pressure at a constant feed flow rate in our experiments. A con siderable impact of the gas pressure on spray performance and steadi ness is assumed for the used atomizers. This hypothesis is based on the different energy level of the atomization gas, compressed to different pressure levels.

\section{Material and methods}

\subsection{Characterization of the model system}

As model system, aqueous solutions of maltodextrin ( $C *$ Dry MD01958, Overlack GmbH, Mönchengladbach, Germany) and recon stituted whey protein concentrate powder (WPC 80, Sachsenmilch $\mathrm{GmbH}$, Leppersdorf, Germany) were used. Maltodextrin is a starch derivate, which is commonly used as matrix material for encapsulation purposes [23]. Moreover, it is a thickener, stabilizer and carbohydrate source. Whey protein concentrates are used as protein source and sur face active agents [24]. In this study, shear viscosity and surface tension of the test solutions were adapted to the properties of whey based protein concentrates (data not shown). The concentration of WPC 80 was fixed to $2 \%$ for all solutions, as this amount was sufficient to reach the required level of surface tension. Total dry matter contents of 40,47 and $50 \%$ were adjusted as combination of WPC 80 and maltodextrin. For calculation of the required amount of water, the powder moisture contents (dry basis) were adapted according to the manufacturer's specifications as $4.50 \%$ (MD) and $4.59 \%$ (WPC). The values were controlled repeatedly during storage by means of a moisture analyzer MLS 65 3A (Kern \& Sohn GmbH, Bahlingen, Germany).

The solutions were characterized by the following parameters: viscosity $(\mu)$, surface tension ( $\sigma)$, density $(\rho)$ and refractive index (RI). All measurements were executed in triplicate at a temperature of $25^{\circ} \mathrm{C}$. Mean values and relative uncertainty values $\mathrm{u}_{\mathrm{r}}(\gamma)$ of these parameters, as well as total dry matter composition of the used solutions are sum marized in Table 1 . The measurement methods and resulting solution properties will be briefly discussed in the following section.

For viscosity measurements, a coaxial cylinder geometry (CC27) in a rotary rheometer (MCR 101/301, Anton Paar GmbH, Graz, Austria) was used. The measurements were conducted at shear rates between 1 and $1000 \mathrm{~s}^{-1}$. In this range, no shear rate dependent flow behavior was detected. The viscosity increases with increasing total dry matter con tent from 0.12 to $0.69 \mathrm{~Pa} \cdot \mathrm{s}$. Surface tensions and densities were mea sured with a Wilhelmy plate system (DCAT 21, DataPhysics Instruments $\mathrm{GmbH}$, Filderstadt, Germany). For all solutions, the surface tension is $0.049 \mathrm{~N} \mathrm{~m}^{-1}$. The density increases with rising total dry matter content from 1185 to $1240 \mathrm{~kg} \mathrm{~m}^{-3}$. The refractive index (RI) of the solutions were measured with a refractometer (Carl Zeiss, Oberkochen, Germany) and increases with increasing total dry matter from 1.404 to 1.427 .

\subsection{Atomizers}

The used IMP atomizer geometries are based on the gas injection geometries, investigated by $[20,12,16,15]$ and $[25,14]$. In order to enable operation in our pilot scale spray dryer (Werco SD20, Hans G. Werner Industrietechnik $\mathrm{GmbH}$, Reutlingen, Germany), the here used atomizers were manufactured from stainless steel. Moreover, a stainless

Table 1

Physical properties viscosity $(\mu)$, surface tension $(\sigma)$, density $(\rho)$ and refractive index (RI), as well as the corresponding uncertainty values $\mathrm{u}_{\mathrm{r}}(\gamma)$ of the test solutions at $25^{\circ} \mathrm{C}$. Concentrations of total dry matter $c_{\text {total }}$, Maltodextrin ( $\left.\mathrm{c}_{\mathrm{MD}}\right)$ and WPC 80 ( $\mathrm{c}_{\text {WPC }} \mathrm{s0}$ ) are given as dry base values (d.b.).

\begin{tabular}{|c|c|c|c|c|c|c|c|c|c|c|}
\hline$c_{\text {total }}(\%$ d.b.) & $\mathrm{c}_{\text {wPC } 80}(\%$ d.b. $)$ & $\mathrm{c}_{\mathrm{MD}}(\%$ d.b. $)$ & $\mu(\mathrm{Pa} \cdot \mathrm{s})$ & $\mathrm{u}_{\mathrm{r}}(\mu)(\%)$ & $\sigma\left(\mathrm{N} \cdot \mathrm{m}^{1}\right)$ & $\mathrm{u}_{\mathrm{r}}(\sigma)(\%)$ & $\rho\left(\mathrm{kg} \cdot \mathrm{m}^{3}\right)$ & $\mathrm{u}_{\mathrm{r}}(\rho)(\%)$ & RI (-) & $\mathrm{u}_{\mathrm{r}}(\mathrm{RI})(\%)$ \\
\hline 40 & 2 & 37 & 0.12 & 7.23 & 0.049 & 0.27 & 1185 & 0.74 & 1.404 & 0.08 \\
\hline 47 & 2 & 45 & 0.39 & 4.61 & 0.049 & 1.03 & 1234 & 0.06 & 1.420 & 0.04 \\
\hline 50 & 2 & 48 & 0.69 & 3.21 & 0.049 & 2.15 & 1240 & 0.48 & 1.427 & 0.03 \\
\hline
\end{tabular}




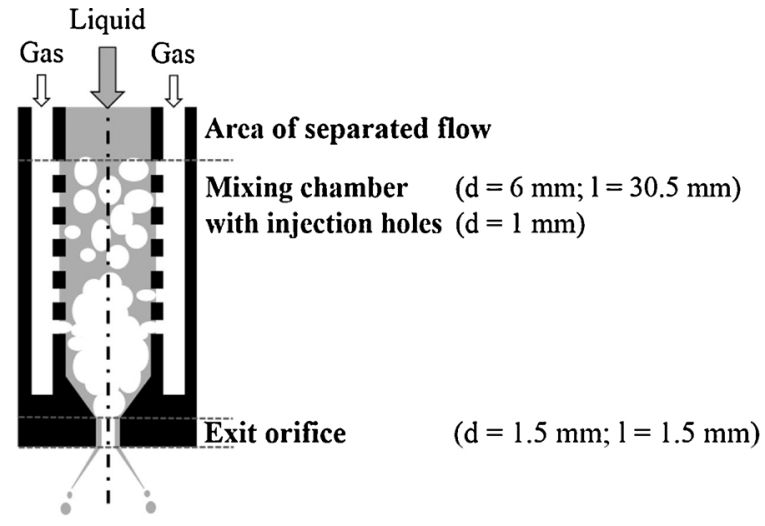

Fig. 1. Scheme of the Effervescent Atomizer (EA).

steel supply pipe was installed between media inputs (gas and liquid) and atomizer geometry, for the same reason. However, comparative tests did not reveal differences in measured spray droplet sizes (data not shown). Details, concerning the gas injection geometries are described in the following section.

\subsubsection{Effervescent atomizer (EA)}

A scheme of the used EA is given in Fig. 1. The atomizer consists of a so called outside in geometry with a single nozzle orifice. The gas in jection geometry is designed according to Huang et al. [26]. The 24 gas injection holes are located in 6 equidistant rings. The injection hole patterns are rotated by $45^{\circ}$, relatively to the neighboring one. Each hole has a diameter of $1 \mathrm{~mm}$, resulting in a total gas injection area of $18.85 \mathrm{~mm}^{2}$. The mixing chamber has a diameter of $6 \mathrm{~mm}$ and a length of $30.5 \mathrm{~mm}$. The exit orifice length and diameter are $1.5 \mathrm{~mm}$.

\subsubsection{Air Core Liquid Ring (ACLR) atomizer}

A scheme of the used ACLR atomizer, is given in Fig. 2. In this atomizer, the gas is injected by a capillary into the liquid stream, shortly before the exit orifice. For this purpose, a gas capillary with a diameter of $1.5 \mathrm{~mm}$ is used, leading to gas injection area of $1.76 \mathrm{~mm}^{2}$. The mixing chamber length is $2.4 \mathrm{~mm}$. The exit orifice dimensions are similar to the EA (length and diameter $1.5 \mathrm{~mm}$ ).

\subsection{Spray test rig}

For spray characterization a modular test rig was used. The liquids were supplied by an eccentric screw pump (MD 006 12, seepex GmbH, Bottrop, Germany). The flow rate was adjusted to $20 \mathrm{~L} / \mathrm{h}$ and measured by a flow meter (VSI 044/16, VSE GmbH, Neuenrade, Germany). The eccentric screw pump produces small fluctuations of liquid flow rate and pressure. The uncertainty value of the liquid flow rate $\mathrm{u}_{\mathrm{r}}(\mathrm{L})$ was below $1 \%$ for all experiments. These fluctuations of the liquid flow are summed up in the uncertainty value of the GLR $\mathrm{u}_{\mathrm{r}}$ (GLR), together with the fluctuations of gas volume flow rates. The liquid pressure was not

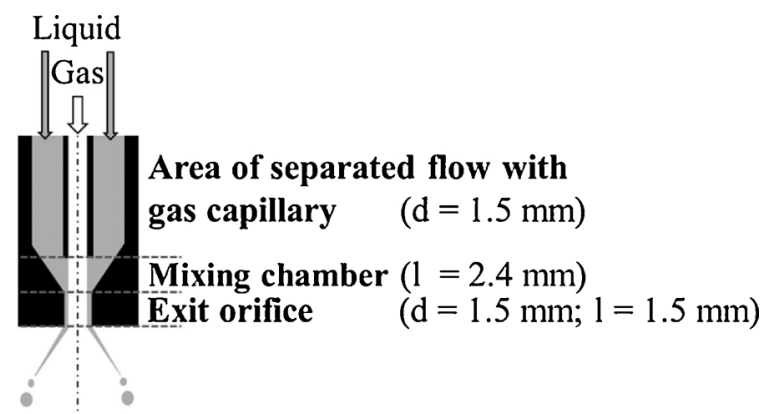

Fig. 2. Scheme of the Air-Core-Liquid-Ring (ACLR) atomizer. monitored in the performed investigations. Compressed air was used as atomization gas. The gas was supplied by a compressor (Renner RSF Top 7.5, Renner GmbH, Güglingen, Germany) with a pressure vessel volume of $90 \mathrm{~L}$. Relative pressures between 0.4 and $0.9 \mathrm{MPa}$ were ad justed by a pressure reducing valve and a pressure gauge. The latter was located shortly upstream the atomizer. The total pressure loss between pressure gauge and atomizer exit is dominated by the pressure loss inside the exit orifice for both used atomizers. As the same exit orifice dimensions are used for both atomizers, it is assumed that the pressure losses are similar in both cases. The gas volume flow, resulting from gas pressure, liquid flow rate and atomizer geometry, was measured by a gas flow meter (ifm SD6000, ifm electronic, Essen, Germany). The atomization of pneumatic atomizers is commonly characterized by the generated spray droplet sizes in relation to the process specific GLR. The GLR was increased by increasing the gas pressure $(0.4,0.5,0.6,0.8$, $0.9 \mathrm{MPa}$ ) at a constant liquid volume flow rate of $20 \mathrm{~L} / \mathrm{h}$. Due to higher gas compression rates, the gas mass flow rates $(G)$ increase with in creasing gas pressures. As the density of the test solutions increases with rising total dry matter content, also the liquid mass flow rate (L) in creases at a constant volume flow rate. Hence, smaller GLRs result when the viscosity is increased at constant gas pressure and constant liquid volume flow. For the investigated atomizers, the mean values of $\mathrm{G}$ and $\mathrm{L}$, as well as the resulting GLR are indicated in Table 2A for the EA and Table $2 \mathrm{~B}$ for the ACLR atomizer. Moreover, the uncertainty value $\mathrm{u}_{\mathrm{r}}(\mathrm{GLR})$ is given. The uncertainty values for $\mathrm{G}$ and $\mathrm{L}$ are not indicated, as $\mathrm{u}_{\mathrm{r}}(\mathrm{GLR})$ sums up fluctuations of the two process parameters.

The spray droplet size was measured with a laser diffraction spec trometer (Spraytec, Malvern Instruments $\mathrm{GmbH}$, Herrenberg, Germany). It was equipped with a $750 \mathrm{~mm}$ focal lens, offering a droplet size measuring range of $22000 \mu \mathrm{m}$. The spectrometer was placed $250 \mathrm{~mm}$ underneath the exit orifice of the used atomizer. The laser beam crossed the full cone spray angle at the nozzle axis centerline. The spray was collected in a vessel below the measurement zone. This vessel was connected to an exhaust fan. In the vessel, a filter was used to prevent recycling of small droplets back into the measurement zone.

\subsection{Droplet size measurement and data analysis}

For the characterization of atomization, the following procedures were used in the presented study: Droplet size measurements by laser diffraction were conducted over $25 \mathrm{~s}$ with a frequency of $250 \mathrm{~Hz}$. This procedure results in 6250 recorded size distributions per measurement. For each size distribution the SMD is determined and the time averaged $\overline{S M D}$ is calculated. This value is commonly used to describe the ato mization performance of an atomizer. In this study we calculated in addition, the number sum distribution $Q_{0}$, SMD of all 6250 SMDs per

\section{Table 2A}

Gas (G) and liquid (L) mass flow rates in the EA at a liquid flow rate of $20 \mathrm{~L} / \mathrm{h}$ and different gas pressures. Investigated solution compositions are indicated by total dry matter content on dry base (d.b.) and viscosity.

\begin{tabular}{|c|c|c|c|c|c|c|c|}
\hline \multirow{2}{*}{$\begin{array}{l}\text { Total dry matter } \\
\text { content (\% d.b.) }\end{array}$} & \multirow{2}{*}{$\begin{array}{l}\text { Viscosity } \\
\text { (Pa:s) }\end{array}$} & \multirow[t]{2}{*}{ Variables } & \multicolumn{5}{|c|}{ Gas pressure (MPa) } \\
\hline & & & 0.4 & 0.5 & 0.6 & 0.8 & 0.9 \\
\hline \multirow[t]{4}{*}{40} & \multirow[t]{4}{*}{0.12} & $\mathrm{G}(\mathrm{kg} / \mathrm{h})$ & 3.7 & 4.6 & 6.0 & 8.5 & 9.9 \\
\hline & & $\mathrm{L}(\mathrm{kg} / \mathrm{h})$ & 23.8 & 23.7 & 23.7 & 23.8 & 23.7 \\
\hline & & GLR (-) & 0.16 & 0.20 & 0.25 & 0.36 & 0.42 \\
\hline & & $\mathrm{u}_{\mathrm{r}}(\mathrm{GLR})(\%)$ & 1.9 & 0.5 & 1.2 & 0.8 & 0.7 \\
\hline \multirow[t]{4}{*}{47} & \multirow[t]{4}{*}{0.39} & $\mathrm{G}(\mathrm{kg} / \mathrm{h})$ & 3.0 & 4.0 & 5.2 & 7.5 & 8.6 \\
\hline & & $\mathrm{L}(\mathrm{kg} / \mathrm{h})$ & 24.8 & 24.8 & 24.8 & 24.8 & 24.8 \\
\hline & & GLR (-) & 0.12 & 0.16 & 0.21 & 0.30 & 0.35 \\
\hline & & $\mathrm{u}_{\mathrm{r}}(\mathrm{GLR})(\%)$ & 1.7 & 1.9 & 1.9 & 1.3 & 2.6 \\
\hline \multirow[t]{4}{*}{50} & \multirow[t]{4}{*}{0.69} & $\mathrm{G}(\mathrm{kg} / \mathrm{h})$ & 2.6 & 3.5 & 4.7 & 6.9 & 8.1 \\
\hline & & $\mathrm{L}(\mathrm{kg} / \mathrm{h})$ & 24.8 & 24.8 & 23.9 & 23.9 & 24.0 \\
\hline & & GLR $(-)$ & 0.11 & 0.14 & 0.19 & 0.29 & 0.34 \\
\hline & & $\mathrm{u}_{\mathrm{r}}(\mathrm{GLR})(\%)$ & 4.5 & 1.4 & 1.1 & 1.4 & 3.8 \\
\hline
\end{tabular}


Table 2B

Gas (G) and liquid (L) mass flow rates in the ACLR atomizer at a liquid flow rate of $20 \mathrm{~L} / \mathrm{h}$ and different gas pressures. Investigated solution compositions are indicated by total dry matter content on dry base (d.b.) and viscosity.

\begin{tabular}{|c|c|c|c|c|c|c|c|}
\hline \multirow{2}{*}{$\begin{array}{l}\text { Total dry matter } \\
\text { content (\% d.b.) }\end{array}$} & \multirow{2}{*}{$\begin{array}{l}\text { Viscosity } \\
\text { (Pa:s) }\end{array}$} & \multirow[t]{2}{*}{ Variables } & \multicolumn{5}{|c|}{ Gas pressure (MPa) } \\
\hline & & & 0.4 & 0.5 & 0.6 & 0.8 & 0.9 \\
\hline \multirow[t]{4}{*}{40} & \multirow[t]{4}{*}{0.12} & $\mathrm{G}(\mathrm{kg} / \mathrm{h})$ & 3.6 & 4.9 & 6.1 & 8.6 & 10.1 \\
\hline & & $\mathrm{L}(\mathrm{kg} / \mathrm{h})$ & 23.8 & 23.8 & 23.9 & 23.8 & 23.8 \\
\hline & & GLR (-) & 0.15 & 0.21 & 0.25 & 0.36 & 0.43 \\
\hline & & $\mathrm{u}_{\mathrm{r}}(\mathrm{GLR})(\%)$ & 2.0 & 3.8 & 4.4 & 1.7 & 4.7 \\
\hline \multirow[t]{4}{*}{47} & \multirow[t]{4}{*}{0.39} & $\mathrm{G}(\mathrm{kg} / \mathrm{h})$ & 3.0 & 4.5 & 5.9 & 8.1 & 9.6 \\
\hline & & $\mathrm{L}(\mathrm{kg} / \mathrm{h})$ & 24.9 & 24.8 & 24.8 & 24.8 & 24.8 \\
\hline & & GLR (-) & 0.12 & 0.18 & 0.24 & 0.33 & 0.39 \\
\hline & & $\mathrm{u}_{\mathrm{r}}(\mathrm{GLR})(\%)$ & 5.8 & 3.3 & 2.1 & 3.0 & 4.6 \\
\hline \multirow[t]{4}{*}{50} & \multirow[t]{4}{*}{0.69} & $\mathrm{G}(\mathrm{kg} / \mathrm{h})$ & 2.7 & 3.5 & 4.7 & 8.9 & 10.0 \\
\hline & & $\mathrm{L}(\mathrm{kg} / \mathrm{h})$ & 24.9 & 25.0 & 25.1 & 25.1 & 24.9 \\
\hline & & GLR (-) & 0.11 & 0.14 & 0.19 & 0.35 & 0.40 \\
\hline & & $\operatorname{ur}(\mathrm{GLR})(\%)$ & 4.5 & 2.9 & 1.1 & 4.3 & 2.8 \\
\hline
\end{tabular}

measurement. Thereof, the characteristic values 5 th percentile $\left(\mathrm{x}_{5,0}\right)$, median $\left(\mathrm{x}_{50,0}\right)$ and 95 th percentile $\left(\mathrm{x}_{95,0}\right)$ can be derived. These values are used to characterize the fluctuation of the SMD over the measure ment time [25]. This procedure allows the evaluation of the atomiza tion steadiness. This is very important for the implementation of ato mizers in spray drying processes, as steady droplet size distributions are required for an undisturbed drying process.

\subsection{Statistical analysis}

All atomization measurements were conducted in triplicate, with exception of the measurement at a viscosity of $0.69 \mathrm{~Pa} \cdot \mathrm{s}$ at a gas pres sure of $0.6 \mathrm{MPa}$, which could only be conducted in duplicate. The effect of the gas pressure on measured SMDs was evaluated by 1 way ANOVA. Scheffé's test was used for comparison of means. In the performed tests, probability of $\mathrm{p}<0.05$ was used for the identification of significant differences.

\section{Results and discussion}

\subsection{Influence of GLR on $\overline{\mathbf{S M D}}$}

In order to illustrate the atomization performance of the ACLR atomizer and the EA, $\overline{S M D}$ s are plotted in dependency of the GLR for solutions with viscosities of 0.12 Pass, 0.39 Pa.s and 0.69 Pa.s in Fig. 3.

As expected the $\overline{S M D}$ decreases with increasing GLR and decreasing viscosity in a non linear way for both atomizers. This behavior is

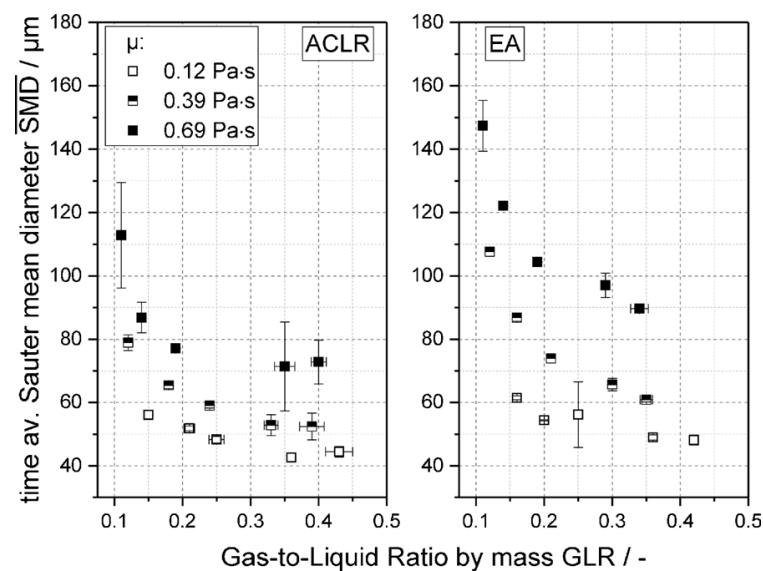

Fig. 3. $\overline{S M D}$ in dependency of the GLR for the ACLR atomizer (left) and the EA (right) for different viscosities., $\mathrm{n}=3$. already described in literature $[7,16,22]$. At low GLRs, the $\overline{S M D}$ de creases strongly with increasing GLR. At higher GLRs, this decrease is lower. For the ACLR atomizer and the solution with a viscosity of $0.12 \mathrm{~Pa} \cdot \mathrm{s}$, the $\overline{S M D}$ decreases from $56 \mu \mathrm{m}$ at a GLR of 0.15 to $43 \mu \mathrm{m}$ at a GLR of 0.36. A further increase of the GLR does not lead to a further reduction of the $\overline{S M D}$. Using the EA with the same solution, a $\overline{S M D}$ of $61 \mu \mathrm{m}$ is achieved at a GLR of 0.16 . The $\overline{S M D}$ decreases to $49 \mu \mathrm{m}$, when the GLR is increased to 0.36 . Also in this case, no further significant decrease was found by an increase of the GLR.

As an increase of viscosity generally complicates atomization, $\overline{S M D} \mathrm{~s}$ increase with increasing viscosity for both atomizers. For instance, at the highest investigated viscosity of $0.69 \mathrm{~Pa} \cdot \mathrm{s}, \overline{S M D} \mathrm{~s}$ increase to $113 \mu \mathrm{m}$ for the ACLR atomizer and $149 \mu \mathrm{m}$ for the EA at a GLR of 0.11 . In any case, the ACLR atomizer produces significantly smaller $\overline{S M D} \mathrm{~s}$ than the EA at comparable GLRs. At the lowest viscosity of $0.12 \mathrm{~Pa}$.s, these dif ferences are quite small. These findings are in accordance to the results of Stähle et al. [16], who found similar $\overline{S M D}$ s for both atomizers up to their maximum investigated viscosity of 0.308 Pa.s. However, in the here presented study, the viscosity was increased up to $0.69 \mathrm{~Pa} \cdot \mathrm{s}$. As a result, also the differences in $\overline{S M D} \mathrm{~s}$ at comparable GLRs increased. Also Stähle et al. expected higher $\overline{S M D} \mathrm{~s}$ when using an EA for atomization of liquids with higher viscosities, than using an ACLR atomizer [16]. This expectation is based on investigations on the two phase flow inside the mixing chamber of the EA. At low GLRs, the favorable annular flow pattern in the EA changes into a plug flow. In this case, the annular flow like pattern is interrupted by liquid bridges, leading to an unsteady atomization result [12]. In the ACLR atomizer, even at low GLRs, an annular flow is enforced due to the nozzle design. Despite these dif ferences in internal flow conditions and resulting spray unsteadiness of both atomizers, the calculated $\overline{S M D}$ values leveled out in the in vestigations of Stähle et al. [16]. It is not clear, which kinds of flow patterns are formed in the EA under the process condition investigated in the here presented study. Nevertheless, it can be assumed, that higher $\overline{S M D} \mathrm{~s}$ result from more pronounced instabilities of flow patterns inside the EA. These instabilities might lead to a shift from symme trically distributed SMDs to skewed distributions, when the EA is op erated under suboptimal processing conditions. If this hypothesis is correct, the sole comparison of $\overline{S M D} \mathrm{~s}$ is not meaningful, as skew dis tributions distort the interpretation of the results. Furthermore, narrow droplet size distributions are required for application in spray drying processes. It is assumed that time dependent fluctuations of the flow pattern inside the exit orifice of an IMP nozzle lead to wide SMD dis tributions, while constant flow conditions lead to narrow distributions. As narrow distributions are crucial for the atomization process, we analyzed the number sum distributions of time dependent SMDs $\left(Q_{0}\right.$, SMD).

\subsection{Number sum distribution of time dependent $S M D s\left(Q_{0}, S M D\right)$}

The fluctuation of SMDs is demonstrated by an exemplary series of measurements at a liquid viscosity of $0.39 \mathrm{~Pa} \cdot \mathrm{s}$. In Fig. 4 the results are plotted as $\mathrm{Q}_{0 \text { SMD }}$ for different gas pressures. The gas pressure $\mathrm{p}_{\mathrm{G}}$ is used as reference parameter instead of the GLR as it is the initially given parameter and not dependent on physical properties of the used solu tions like the GLR (see Tables 1, 2A and 2B). For clarity only dis tributions at gas pressures of 0.40 .6 and $0.8 \mathrm{MPa}$ are shown. A further increase of the gas pressure to $0.9 \mathrm{MPa}$ did not lead to any significant changes in the distribution. Results at gas pressures of $0.5 \mathrm{MPa}$ were in the trend between 0.4 and $0.6 \mathrm{MPa}$ in all cases. Using the ACLR ato mizer, narrow SMD distributions are found for all applied gas pressures. An increase of the gas pressure leads to a shift of the size distribution to smaller values and the distribution widths is almost constant. This re sult is in accordance with the assumption, that steady flow conditions inside the exit orifice, as induced by the ACLR geometry, lead to narrow and symmetrically shaped SMD distributions. In contrast to the results of the ACLR atomizer, a clear influence of the gas pressure on the 


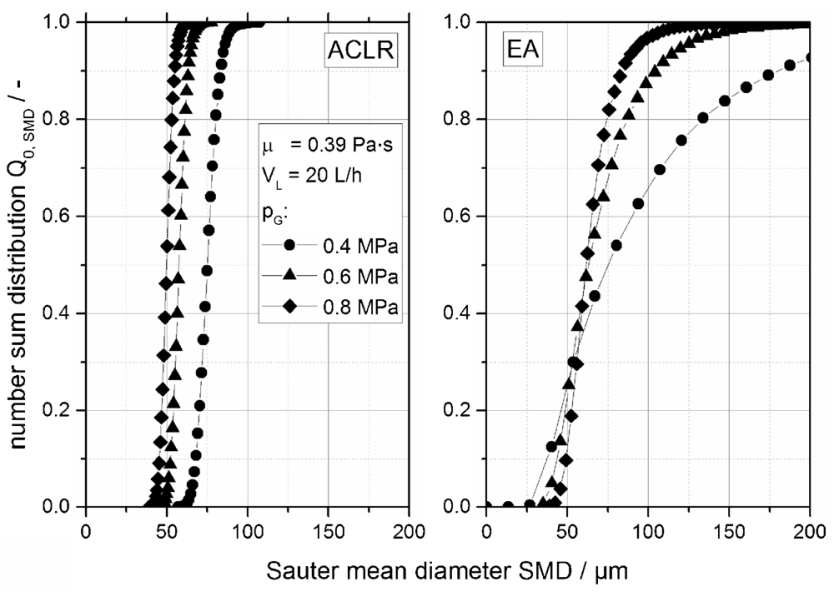

Fig. 4. Exemplary series of $Q_{0}, S_{D}$ in dependency of the gas pressure $p_{C}$ (0.4 MPa, 0.6 MPa, 0.8 MPa) for the ACLR atomizer (left) and the EA (right). Values are plotted for the liquid viscosity of $0.39 \mathrm{~Pa} \cdot \mathrm{s}$.

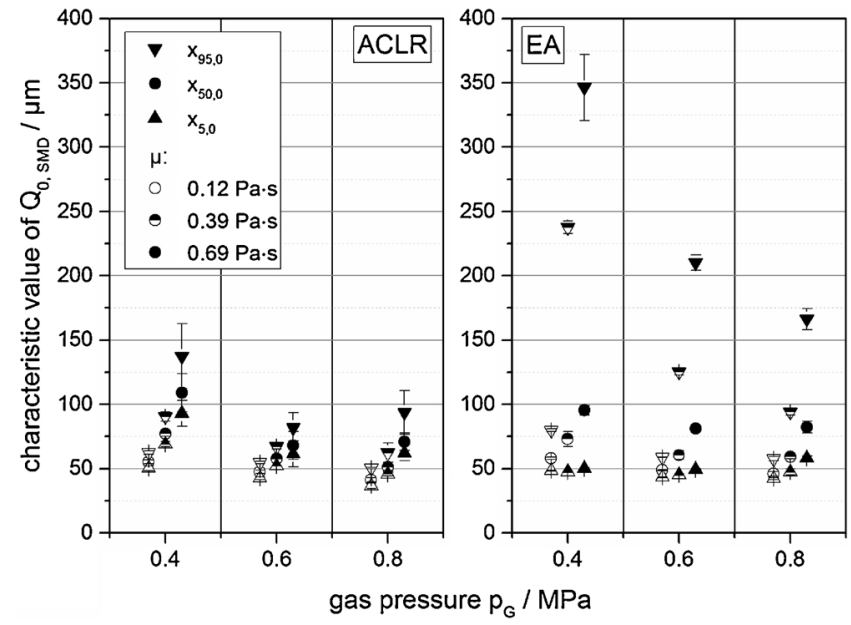

Fig. 5. Characteristic values 5 th percentile $\left(x_{5,0}\right)$, median $\left(x_{50,0}\right)$ and 95 th percentile $\left(x_{95,0}\right)$ of SMD distributions $\left(Q_{0, S M D}\right)$ in dependency of the gas pressure $\mathrm{p}_{\mathrm{G}}(0.4 \mathrm{MPa}, 0.6 \mathrm{MPa}, 0.8 \mathrm{MPa})$ for the ACLR atomizer (left) and the EA (right). Values are plotted for liquid viscosities of $0.12,0.39$ and 0.69 Pa.s. distribution widths was found for the EA. For this atomizer, the dis tribution of SMDs at a gas pressure of $0.4 \mathrm{MPa}$ is comparably wide and clearly non symmetrically. An increase of the gas pressure does not lead to a parallel shift of the distribution, but to a clear reduction of large SMDs. Moreover, increasing the gas pressure leads to a slight increase of the smallest SMDs. Consequently, the distribution width, as well as the median value are reduced, leading to a reduced skewness of $\mathrm{Q}_{0}$, sMD. This is most likely based on changes in the two phase flow pattern in side the exit orifice of the EA [20]. However, these findings have not been proven under the here investigated conditions, yet. Therefore, further investigations on the two phase flows inside the exit orifice of both atomizers should be undertaken.

In order to allow an easier comparison of the shape of several $Q_{0}$, SMD distributions at different process conditions, the characteristic va lues 5 th percentile $\left(\mathrm{x}_{5,0}\right)$, median $\left(\mathrm{x}_{50,0}\right)$ and 95 th percentile $\left(\mathrm{x}_{95,0}\right)$ are derived for the next chapter. By means of these values, the shape of $\mathrm{Q}_{0, \mathrm{SMD}}$, and therefore the time dependent fluctuation of SMDs, can be evaluated. In symmetrical distributions the median value $x_{50,0}$ is in the middle between $x_{5,0}$ and $x_{95,0}$. If this is true, we assume that changes of internal flow patterns are very unlikely. In addition, the calculation of arithmetic mean values is suitable in this case. Generally, in skew dis tributions the median value is shifted in direction of $x_{5,0}$ or $x_{95,0}$. In skew SMD distributions, based on a plug flow inside the atomizer, the median value is most likely shifted to higher SMDs. This assumption can be made, as atomization is drastically hindered for short time, when liquid bridges pass the exit orifice. In order to shift the median value in direction of $\mathrm{x}_{5,0}$, a short improvement of the atomization conditions would be necessary. From all we know on internal flow conditions of IMP atomizers so far, this case is very unlikely. Anyhow, in case of skew distributions, the sole indication of the arithmetic mean deprives im portant information on the atomization performance. Hence, atomiza tion results will be characterized in the next section by the median value $\mathrm{x}_{50,0}$ and the width of the SMD distribution $\mathrm{Q}_{0, \mathrm{SMD}}$, represented by the spread of $x_{95,0}$ and $x_{5,0}$.

\subsection{Influence of the liquid viscosity on the fluctuation of SMDs}

In Fig. 5 , the characteristic values $\mathrm{x}_{5,0}, \mathrm{x}_{50,0}$ and $\mathrm{x}_{95,0}$ of $\mathrm{Q}_{0, \mathrm{SMD}}$ are shown for the liquids with viscosities of $0.12,0.39$ and $0.69 \mathrm{~Pa} \cdot \mathrm{s}$ in dependency of the gas pressure for the ACLR atomizer (left) and the EA (right). Moreover, the so called point shift technique is used, in order to improve the readability of the diagram. This means that data points are shifted around the given gas pressure of $0.4,0.6$ and $0.8 \mathrm{MPa}$ respec tively. Nevertheless, although they are shifted, all values in one group where processed at the same pressure. Within one group of results,

Table 3A

Characteristic values $\mathrm{x}_{5,0}, \mathrm{x}_{50,0}$ and $\mathrm{x}_{95,0}$ of $\mathrm{Q}_{0}$, sMD in dependency of the gas pressure $\mathrm{p}_{\mathrm{G}}(0.4 \mathrm{MPa}, 0.6 \mathrm{MPa}, 0.8 \mathrm{MPa})$ as well as the corresponding uncertainty values $\mathrm{u}_{\mathrm{r}}$ for the EA. Moreover, $\overline{S M D} \mathrm{~s}$ corresponding uncertainty values $\mathrm{u}_{\mathrm{r} \text {. }}$ are indicated (see Fig. 3 ).

Gas pressure (MPa)

\begin{tabular}{|c|c|c|c|c|c|c|c|}
\hline \multirow[t]{2}{*}{ Viscosity (Pa's) } & char. & 0.4 & & 0.6 & & 0.8 & \\
\hline & $\begin{array}{l}\text { values of } \\
Q_{0, S M D}\end{array}$ & mean & $\mathrm{u}_{\mathrm{r}}$ & mean & $\mathrm{u}_{\mathrm{r}}$ & mean & $\mathrm{u}_{\mathrm{r}}$ \\
\hline \multirow[t]{3}{*}{0.12} & $\mathrm{x}_{5,0}$ & 48 & 0.8 & 43 & 0.7 & 42 & 2.1 \\
\hline & $\mathrm{x}_{50,0} \mid \overline{S M D}$ & $58 \mid 61$ & $1.7 \mid 1.1$ & 49 | 56 & $0.8 \mid 18.5$ & $46 \mid 49$ & $4.0 \mid 1.8$ \\
\hline & $\mathrm{x}_{95,0}$ & 80 & 1.3 & 59 & 0.4 & 58 & 2.8 \\
\hline \multirow[t]{3}{*}{0.39} & $\mathrm{x}_{5,0}$ & 47 & 1.3 & 45 & 1.3 & 47 & 5.1 \\
\hline & $\mathrm{x}_{50,0} \mid \overline{S M D}$ & $73 \mid 108$ & $8.2 \mid 1.4$ & $60 \mid 74$ & $5.3 \mid 2.0$ & $59 \mid 66$ & $2.4 \mid 3.1$ \\
\hline & $\mathrm{X}_{95,0}$ & 238 & 2.1 & 125 & 2.0 & 94 & 2.4 \\
\hline \multirow[t]{3}{*}{0.69} & $\mathrm{x}_{5,0}$ & 50 & 1.3 & 49 & 0.6 & 58 & 3.0 \\
\hline & $\mathrm{x}_{50,0} \mid \overline{S M D}$ & $95.3 \mid 147$ & $3.8 \mid 5.5$ & $81 \mid 104$ & $1.9 \mid 1.4$ & $82 \mid 97$ & $5.8 \mid 0.5$ \\
\hline & $\mathrm{x}_{95,0}$ & 346 & 7.4 & 210 & 2.9 & 166 & 5.0 \\
\hline
\end{tabular}


Table 3B

Characteristic values $\mathrm{x}_{5,0}, \mathrm{x}_{50,0}$ and $\mathrm{x}_{95,0}$ of $\mathrm{Q}_{0}$, SMD in dependency of the gas pressure $\mathrm{p}_{\mathrm{G}}(0.4 \mathrm{MPa}, 0.6 \mathrm{MPa}, 0.8 \mathrm{MPa})$ as well as the corresponding uncertainty values $\mathrm{u}_{\mathrm{r} \text {. }}$ for the ACLR atomizer. Moreover, $\overline{S M D} \mathrm{~s}$ corresponding uncertainty values $\mathrm{u}_{\mathrm{r} \text {. }}$ are indicated (see Fig. 3).

\begin{tabular}{|c|c|c|c|c|c|c|c|}
\hline \multirow{3}{*}{ Viscosity (Pa:s) } & \multirow{3}{*}{$\begin{array}{l}\text { char. values } \\
\text { of } Q_{0, S M D}\end{array}$} & \multicolumn{6}{|c|}{ Gas pressure (Mpa) } \\
\hline & & 0.4 & & 0.6 & & 0.8 & \\
\hline & & mean & $\mathrm{u}_{\mathrm{r}}$ & mean & $\mathrm{u}_{\mathrm{r}}$ & mean & $\mathrm{u}_{\mathrm{r}}$ \\
\hline \multirow[t]{3}{*}{0.12} & $x_{5,0}$ & 50 & 3.5 & 42 & 2.8 & 37 & 6.2 \\
\hline & $\mathrm{x}_{50,0} \mid \overline{S M D}$ & $55 \mid 56$ & $2.7 \mid 2.7$ & $47 \mid 48$ & $2.4 \mid 2.2$ & $41 \mid 43$ & 3.9 | 3.3 \\
\hline & $\mathrm{x}_{95,0}$ & 62 & 2.2 & 55 & 1.6 & 50 & 0.9 \\
\hline \multirow[t]{3}{*}{0.39} & $x_{5,0}$ & 69 & 2.9 & 52 & 0.5 & 46 & 2.9 \\
\hline & $\mathrm{x}_{50,0} \mid \overline{S M D}$ & $77 \mid 79$ & $2.6 \mid 3.2$ & $58 \mid 59$ & $0.2 \mid 1.3$ & $51 \mid 53$ & 4.4 | 6.2 \\
\hline & $\mathrm{x}_{95,0}$ & 90 & 3.9 & 67 & 2.9 & 62 & 12.1 \\
\hline \multirow[t]{3}{*}{0.69} & $x_{5,0}$ & 93 & 10.9 & 61 & 16.3 & 62 & 10.1 \\
\hline & $\mathrm{x}_{50,0} \mid \overline{S M D}$ & $109 \mid 113$ & $13.7 \mid 14.8$ & $68 \mid 77$ & $16.0 \mid 0.2$ & $71 \mid 71$ & $9.5 \mid 19.8$ \\
\hline & $x_{95,0}$ & 137 & 18.3 & 82 & 14.4 & 94 & 18.2 \\
\hline
\end{tabular}

values for $\mu=0.12 \mathrm{~Pa} \cdot \mathrm{s}$ are shifted to the left and values for $\mu=0.69 \mathrm{~Pa} \cdot \mathrm{s}$ are shifted to the right. Results for $\mu=0.39 \mathrm{~Pa}$.s remained in the middle.

Regarding the characteristic values of $\mathrm{Q}_{0, \mathrm{SMD}}$ for each atomizer at constant gas pressure, the following trends can be derived. All char acteristic values of $\mathrm{Q}_{0, \mathrm{SMD}}$ increase significantly with increasing visc osity. In addition the spread between $x_{5,0}$ and $x_{95,0}$ increases with in creasing viscosity. Thus, wider distributions of the SMD are generated, when liquids with higher viscosities are atomized under the same gas pressure. These trends are valid for all investigated gas pressures and for both atomizers (See Tables 3A and Table 3B). However, at viscos ities above 0.12 Pa.s, width and skewness of SMD distributions increase drastically when the EA is used, instead of the ACLR atomizer.

Considering the effect of increasing gas pressure at constant visc osity, the characteristic values significantly decrease with increasing gas pressure, when the ACLR atomizer is used. Exceptions are the fol lowing cases: At the viscosity of $0.39 \mathrm{~Pa} \cdot \mathrm{s}$ no significant decrease of $\mathrm{x}_{95,0}$ was observed when the gas pressure was increased from 0.6 to $0.8 \mathrm{MPa}$. At a viscosity of $0.69 \mathrm{~Pa} \cdot \mathrm{s}, \mathrm{x}_{95,0}$ did not decrease significantly with in creasing gas pressure over the complete investigated range. Additionally, no significant reduction of the three considered char acteristic values was observed at this viscosity, when the gas pressure was increased from 0.6 to $0.8 \mathrm{MPa}$. In contrast, an increase of the gas pressure from 0.4 to $0.6 \mathrm{MPa}$ and further to $0.8 \mathrm{MPa}$ resulted in sig nificant decreases of $\mathrm{x}_{95,0}$ in each step, when the EA was used at visc osities larger than 0.12 Pa.s. Nevertheless, the ACLR atomizer delivered smaller median values, as well as smaller distribution widths in all in vestigated cases, compared to the EA. For comparison, all plotted va lues, as well as corresponding $\overline{S M D}$ s (see Fig. 3) are given Tables $3 \mathrm{~A}$ (EA) and 3B (ACLR atomizer).

As mentioned before, arithmetic means $(\overline{S M D})$ and medians $\left(\mathrm{x}_{50,0}\right)$ have the same values for exact symmetric distributions. Hence, with increasing skewness of a distribution, the difference between, $\overline{S M D}$ and $\mathrm{x}_{50,0}$ increases. In that case, the arithmetic mean is not suitable to characterize the spray performance. This effect is clearly observable in the results of the EA at viscosities larger than 0.12 Pas. For the ACLR atomizer, only small differences between $\overline{S M D}$ and $\mathrm{x}_{50,0}$ are found. Consequently, $\overline{S M D}$ should not be used to characterize the atomization performance of the EA under the here investigated conditions. The comparably strong fluctuations of the SMD and the resulting skewness of its distribution in operation of the EA might be a hint on changes of the two phase flow pattern inside the mixing chamber and the exit orifice of the atomizer. Concerning the ACLR atomizer, the here pre sented measurements strengthen the assumption of an enforced annular flow, as only small fluctuations of the SMDs are measured. These findings are generally in common with the results discussed in chapter 3.1. However, the here presented analysis of $\mathrm{Q}_{0, \mathrm{SMD}}$ in dependency of $\mathrm{p}_{\mathrm{G}}$ gives a much better understanding of an atomizer's spray performance than the commonly considered dependency between GLR and $\overline{S M D}$ (see Fig. 3). Although the impact of gas pressure on the two phase flow inside the exit orifice of ACLR atomizer s still has to be investigated in detail, the here presented results show, that ACLR ato mizer concept is promising for the application in spray drying of high viscous feed liquids. The EA is not suitable for this application, as strong fluctuations of the SMD were observed at higher viscosities. Theses fluctuations of the SMD are based on even stronger fluctuations of the original spray droplet size distributions, leading to strong disturbances of the spray drying process.

\section{Conclusion}

In the presented study, the potential for the use of an EA and an ACLR atomizer for spray drying of high viscous feed liquids was investigated. In the atomization step of spray drying processes, steady and narrow spray droplet size distribution are required, in order to avoid disturbances of the subsequent drying step. Therefore, the impact of different gas pressures on spray performance and steadiness were investigated at viscosities up to $0.69 \mathrm{~Pa}$ s. As steady atomization to narrow droplet size distributions is crucial for spray drying applications, we evaluated not only the correlation between GLR and $\overline{S M D}$ as usually done but analyzed the time dependent steadiness of SMDs. Therefore we derived a number sum distribution of SMDs ( $Q_{0, S M D}$ ), as well as the characteristic values $x_{5,0}, x_{90,0}$ and $x_{95,0}$ from 6250 single droplet size distributions measured within $25 \mathrm{~s}$.

Using the ACLR atomizer, an increase of the applied gas pressure leads to a parallel shift of $\mathrm{Q}_{0, \mathrm{SMD}}$ to smaller values. The distribution width, represented by the difference between the characteristic values $\mathrm{x}_{5,0}$ and $\mathrm{x}_{95,0}$, is not influenced in the investigated parameter range. Using the EA, increasing gas pressures mainly lead to a reduction of very large SMDs, instead of a shift of the distribution in direction of smaller values. Consequently, the width of $\mathrm{Q}_{0, \mathrm{SMD}}$ is significantly re duced by increased gas pressures but the median $\mathrm{x}_{50,0}$ decreases less than in case of using the ACLR atomizer. Higher viscosities result in higher mean values and stronger fluctuations of SMDs, in comparison to the ACLR atomizer. It is hypothesized that these differences are based on an unsteady two phase flow regimes in the EA in contrast to an enforced annular flow in the ACLR atomizer even at high viscosities a low GLRs.

Summing up the presented facts, the EA is not suitable for the aimed application in spray drying of highly concentrated feed liquids, due strong fluctuations of the produced SMDs under spray drying relevant processing conditions. In contrast, the ACLR atomizer is a very promising nozzle for this challenging task, as it delivers much better performance and steadiness, also at high liquid viscosities. Further work will be addressed to transfer this kind of atomizer into spray drying processes. Therefore, a better under standing of the correlations between process parameters, flow conditions inside the atomizer and atomization performance is still required. 


\section{Acknowledgements}

The IGF Project AiF $18299 \mathrm{~N}$ of the FEI was supported via AiF within the programme for promoting the Industrial Collective Research (IGF) of the German Ministry of Economic Affairs and Energy (BMWi), based on a resolution of the German Parliament. The authors further express their thanks to Sabine Mizera, Stefanie Milles and Andrea Butterbrodt for experimental support.

\section{References}

[1] Arun S. Mujumdar, Handbook of Industrial Drying. 4. Aufl (Hg.), CRC Press, Boca Raton, 2015.

[2] C.G.J. Baker, K.A. McKenzie, Energy consumption of industrial spray dryers, Drying Technology 23 (1-2 SPEC. ISS, (2005), pp. 365-386, http://dx.doi.org/10.1081/ DRT-200047665.

[3] I.C. Kemp, Reducing dryer energy use by process integration and pinch analysis, Drying Technol. 23 (9-11) (2005) S2089-S2104, http://dx.doi.org/10.1080/ 07373930500210572.

[4] K. Masters, Spray Drying in Practice. Charlottenlund/DK: SprayDryConsult International ApS, (2002).

[5] V. Westergaard, Milk Powder Technology: Evaporation and Spray Drying. Kopenhagen: Niro A/S (5), (2004)

[6] L.P. Bayvel, Z. Orzechowski, Liquid Atomization, Taylor \& Francis, Washington, DC, 1993.

[7] S.D. Sovani, P.E. Sojka, A.H. Lefebvre, Effervescent atomization, Prog. Energy Combust. Sci. 27 (4) (2001) S483-S521.

[8] Marek Mlkvik, Philipp Stähle, Volker Gaukel, Matouš Zaremba, Jan Jedelský, Miroslav Jícha, et al., Performance of twin-fluid atomizers for atomization of viscous solutions, EPJ Web of Conferences 92 (2015) 2052, http://dx.doi.org/10 1051/epjconf/20159202052.

[9] Marek Mlkvik, Philipp Stähle, Heike P. Schuchmann, Volker Gaukel, Jan Jedelsky, Miroslav Jicha, Twin-fluid atomization of viscous liquids. The effect of atomizer construction on breakup process, spray stability and droplet size, Int. J. Multiphase Flow (77) (2015) S19-S31, http://dx.doi.org/10.1016/j.ijmultiphaseflow.2015.06. 010 .

[10] Jan Jedelský, Miroslav Jícha, Spray characteristics and liquid distribution of multihole effervescent atomisers for industrial burners, Appl. Therm. Eng. 96 (2016) 286-296, http://dx.doi.org/10.1016/j.applthermaleng.2015.11.079.

[11] Matouš Zaremba, Lukas Weiß, Milan Malý, Michael Wensing, Jan Jedelský, Miroslav Jícha, Low-pressure twin-fluid atomization. Effect of mixing process on spray formation, Int. J. Multiphase Flow 89 (2017) S277-S289, http://dx.doi.org/ 10.1016/j.ijmultiphaseflow.2016.10.015.

[12] Philipp Stähle, Volker Gaukel, Heike P. Schuchmann, Investigation on the applicability of the effervescent atomizer in spray drying of foods. Influence of liquid viscosity on nozzle internal two-phase flow and spray characteristics, J. Food Process. Eng. 38 (5) (2015) S474-S487, http://dx.doi.org/10.1111/jfpe.12178.

[13] Jewe; Schröder, Fabian Werner, Volker Gaukel, Heike P. Schuchmann, Impact of effervescent atomization on oil drop size distribution of atomized oil-in-water emulsions, Procedia Food Sci. 1 (2011) S138-S144, http://dx.doi.org/10.1016/j. profoo.2011.09.022.

[14] Agnes Kleinhans, Barbara Hornfischer, Volker Gaukel, Heike P. Schuchmann, Influence of viscosity ratio and initial oil drop size on the oil drop breakup during effervescent atomization, Chem. Eng. Process. Process Intensif. 109 (2016) S149-S157, http://dx.doi.org/10.1016/j.cep.2016.09.006.

[15] Philipp Stähle, Jewe Schröder, Agnes; Kleinhans, Heike P. Schuchmann, Volker Gaukel, Effervescent atomization. A new atomizing technique for the energy-efficient spray drying of food liquids with high viscosity, Int. Dairy Mag. 44 (8) (2013) S26-S28.

[16] Philipp Stähle, Volker Gaukel, Heike P. Schuchmann, Comparison of an effervescent nozzle and a proposed air-core-liquid-ring (ACLR) nozzle for atomization of viscous food liquids at Low air consumption, J. Food Process Eng. 40 (1) (2017), http://dx. doi.org/10.1111/jfpe.12268.

[17] J.S. Chin, A.H. Lefebvre, A design procedure for effervescent atomizers, J. Eng. Gas Turbines Power 117 (2) (1995) 266, http://dx.doi.org/10.1115/1.2814090.

[18] C.A. Catlin, J. Swithenbank, Physical processes influencing effervescent atomizer performance in the slug and annular flow regimes, Atomization Sprays 11 (5) (2001) 575-595, http://dx.doi.org/10.1615/atomizspr.v11.i5.60.

[19] J.Y. Kim, S.Y. Lee, Dependence of spraying performance on the internal flow pattern in effervescent atomizers, Atomization Sprays 11 (6) (2001) S735-S756.

[20] Philipp Stähle, Volker Gaukel, Heike P. Schuchmann, Influence of feed viscosity on the two-phase flow inside the exit orifice of an effervescent atomizer and on resulting spray characteristics, Food Res. Int. 77 (2015) S55-S62, http://dx.doi.org/ 10.1016/j.foodres.2015.04.047.

[21] O. Baker, Simultaneous flow of oil and gas, Oil Gas J. Int. Pet. News. Technol. 53 (1954) 185-194.

[22] D. Konstantinov, R. Marsh, P.J. Bowen, A. Crayford, Effervescent atomization for industrial energy-technology review, Atomization Sprays 20 (6) (2010) S525-S552, http://dx.doi.org/10.1615/AtomizSpr.v20.i6.40.

[23] Seid Mahdi Jafari, Elham Assadpoor, Yinghe He, Bhesh Bhandari, Encapsulation efficiency of food flavours and oils during spray drying, Drying Technol. 26 (7) (2008) 816-835, http://dx.doi.org/10.1080/07373930802135972.

[24] Manjula Nishanthi, Jayani Chandrapala, Todor Vasiljevic, Properties of whey protein concentrate powders obtained by spray drying of sweet, salty and acid whey under varying storage conditions, J. Food Eng. 214 (2017) S137-S146, http://dx. doi.org/10.1016/j.jfoodeng.2017.06.032.

[25] Agnes Kleinhans, Kostadinka Georgieva, Moritz Wagner, Volker Gaukel, Heike P. Schuchmann, On the characterization of spray unsteadiness and its influence on oil drop breakup during effervescent atomization, Chem. Eng. Process. Process Intensif. 104 (2016) S212-S218, http://dx.doi.org/10.1016/j.cep.2016.03.011.

[26] X. Huang, X. Wang, G. Liao, Visualization of two phase flow inside an effervescent atomizer, J. Vis. 11 (4) (2008) 299-308, http://dx.doi.org/10.1007/BF03182198. 


\section{Repository KITopen}

Dies ist ein Postprint/begutachtetes Manuskript.

Empfohlene Zitierung:

Wittner, M. O.; Karbstein, H. P.; Gaukel, V.

Spray performance and steadiness of an effervescent atomizer and an air-core-liquid-ring atomizer for application in spray drying processes of highly concentrated feeds.

2018. Chemical engineering and processing, 128.

doi: $10.5445 / / R / 1000085846$

Zitierung der Originalveröffentlichung:

Wittner, M. O.; Karbstein, H. P.; Gaukel, V.

Spray performance and steadiness of an effervescent atomizer and an air-core-liquid-ring atomizer for application in spray drying processes of highly concentrated feeds.

2018. Chemical engineering and processing, 128, 96-102.

doi:10.1016/j.cep.2018.04.017 